Article

\title{
Genetic Relatedness, Antibiotic Resistance, and Effect of Silver Nanoparticle on Biofilm Formation by Clostridium perfringens Isolated from Chickens, Pigeons, Camels, and Human Consumers
}

\author{
Heba A. Ahmed ${ }^{1, *}$ D, Rasha M. El Bayomi ${ }^{2}$, Rehab I. Hamed ${ }^{3}$, Rasha A. Mohsen ${ }^{4}$, Fatma A. El-Gohary ${ }^{5}$, \\ Ahmed A. Hefny ${ }^{6}$, Eman Elkhawaga ${ }^{7}$ and Hala M. N. Tolba ${ }^{8}$ (D)
}

check for updates

Citation: Ahmed, H.A.; El Bayomi, R.M.; Hamed, R.I.; Mohsen, R.A.;

El-Gohary, F.A.; Hefny, A.A.;

Elkhawaga, E.; Tolba, H.M.N. Genetic

Relatedness, Antibiotic Resistance, and Effect of Silver Nanoparticle on Biofilm Formation by Clostridium perfringens Isolated from Chickens,

Pigeons, Camels, and Human

Consumers. Vet. Sci. 2022, 9, 109.

https://doi.org/10.3390/

vetsci9030109

Academic Editor: Valentina Virginia Ebani

Received: 29 January 2022

Accepted: 27 February 2022

Published: 2 March 2022

Publisher's Note: MDPI stays neutral with regard to jurisdictional claims in published maps and institutional affiliations.

Copyright: (C) 2022 by the authors Licensee MDPI, Basel, Switzerland. This article is an open access article distributed under the terms and conditions of the Creative Commons Attribution (CC BY) license (https:// creativecommons.org/licenses/by/ $4.0 /)$.
1 Department of Zoonoses, Faculty of Veterinary Medicine, Zagazig University, Zagazig 44511, Egypt

2 Department of Food Control, Faculty of Veterinary Medicine, Zagazig University, Zagazig 44511, Egypt; rmazab_2010@yahoo.com

3 Reference Laboratory for Quality Control on Poultry Production, Department of Poultry Diseases, Animal Health Research Institute, Zagazig Branch, Agriculture Research Center (ARC), Zagazig 44516, Egypt; rehab.44444@yahoo.com

4 Department of Bacteriology, Animal Health Research Institute, Mansoura Branch, Agriculture Research Center (ARC), Mansoura 12618,Egypt; rasha.mohsen@hotmail.com

5 Department of Hygiene and Zoonoses, Faculty of Veterinary Medicine, Mansoura University, Mansoura 35516, Egypt; dr.fatmagohary@gmail.com

6 Veterinary Hospital, Faculty of Veterinary Medicine, Zagazig University, Zagazig 44511, Egypt; ahmed_vet8_2007@yahoo.com

7 Department of Food Hygiene, Animal Health Research Institute, Mansoura Branch, Agriculture Research Center (ARC), Mansoura 12618, Egypt; emanelkhawaga@yahoo.com

8 Department of Avian and Rabbit Medicine, Faculty of Veterinary Medicine, Zagazig University, Zagazig 44511, Egypt; moonfacem2000@yahoo.com

* Correspondence: heba_ahmed@zu.edu.eg

\begin{abstract}
In this study, we determined the prevalence and toxin types of antibiotic-resistant Clostridium perfringens in chicken, pigeons, camels, and humans. We investigated the inhibitory effects of AgNPs on biofilm formation ability of the isolates and the genetic relatedness of the isolates from various sources determined using RAPD-PCR. Fifty isolates were identified using PCR, and all the isolates were of type A. The cpe and $c p b 2$ genes were detected in $12 \%$ and $56 \%$ of the isolates, respectively. The effect of AgNPs on biofilm production of six representative isolates indicated that at the highest concentration of AgNPs $(100 \mu \mathrm{g} / \mathrm{mL})$, the inhibition percentages were $80.8-82.8 \%$. The RAPD-PCR patterns of the 50 C. perfringens isolates from various sources revealed 33 profiles and four clusters, and the discriminatory power of RAPD-PCR was high. Multidrugresistant $C$. perfringens isolates are predominant in the study area. The inhibition of biofilm formation by $C$. perfringens isolates was dose-dependent, and RAPD-PCR is a promising method for studying the genetic relatedness between the isolates from various sources. This is the first report of AgNPs' anti-biofilm activity against $C$. perfringens from chickens, pigeons, camels, and humans, to the best of our knowledge.
\end{abstract}

Keywords: Clostridium perfringens; toxinotyping; biofilm inhibition; silver nanoparticles; RAPDPCR genotyping

\section{Introduction}

Clostridium perfringens is a Gram-positive anaerobic pathogen that inhabits the intestine of various animal species and humans. Necrotic enteritis (NE) is considered the main lesion caused by the organism in chickens and pigeons. The disease is fatal, and the main clinical manifestations include anorexia, depression, decreased growth performance, and reduced 
feed efficiency, thus resulting in severe economic loss [1]. In domestic animals, such as camels, the organism causes enterotoxemia, diarrhea, and sudden death [2].

In humans, C. perfringens causes gas gangrene, food poisoning, and gastrointestinal illnesses, including sporadic diarrhea, nosocomial diarrheal diseases, and antibioticassociated diarrhea due to consumption of contaminated food with enterotoxin-producing strains [3,4]. Therefore, the presence of $C$. perfringens with a high count $\left(>10^{6} \mathrm{CFU} / \mathrm{g}\right.$ feces) is an indicator of $C$. perfringens food poisoning $[5,6]$.

Five genotypes (A-E) have been recognized for C. perfringens based on the four main toxins (alpha, beta, epsilon, and iota toxins). Two other toxin types ( $F$ and $G$ ) have been recorded [7]. The most prevalent toxin is alpha-toxin, produced by all C. perfringens types and encoded by the cpa gene [8]. C. perfringens also produce other toxins that contribute to food poisoning and gastroenteritis in animals and humans. These toxins include enterotoxin, beta2 toxin, and perfringolysin $\mathrm{O}$, which are encoded by the cpe, $c p b 2$, and $p f o$ genes, respectively [9]. The main virulence factor implicated in human food poisoning is enterotoxin [10], while the beta2 toxin has been associated with enteric diseases in humans and animals. However, the toxin-associated gene has also been found in isolates recovered from obviously healthy animals [11].

The economic losses caused by C. perfringens can be reduced using antibiotics, such as chloramphenicol, metronidazole, tetracycline, ampicillin, and imipenem to control bacterial infection. However, this has caused a significant increase in C. perfringens resistance to lincomycin, tetracycline, and erythromycin [12].

Several reports have described enhanced antimicrobial resistance among anaerobes and thus reduced susceptibility of clinical isolates to therapy [13]. The reason for the increased resistance is the uncontrolled use of antibiotics in animal production as growth promoters. This causes the emergence of multiple drug-resistant (MDR) isolates and the transfer of antimicrobial residues from livestock to humans, posing harm to consumers [12]. Therefore, the World Health Organization recommended the replacement of antibiotics with alternative strategies for growth promotion [14].

Biofilms are surface-related bacterial communities formed due to the adhesion of bacteria to surfaces and subsequent production of extracellular polymeric substances (EPs) [15]. The ability of bacteria to cluster and attach to themselves and be embedded in a self-produced matrix has been reported. The biofilm matrix is formed of polysaccharides, DNA, and proteins [16]. This matrix protects the bacteria against body defense mechanisms, and the effect of antibiotics and disinfectants. The biofilm layer enables the microbe to cause different diseases. Thus, $65-80 \%$ of infections are estimated to be caused by biofilm-forming bacteria [17].

Due to the smaller size and higher surface area to volume ratio, nanoparticles (NPs) have been investigated for their antibacterial and anti-biofilm effects [18]. Recently, the role of nanoparticles has been documented to overcome the limitations of antibiotics in controlling infections. Silver nanoparticles (AgNPs) have a biocidal effect on various foodborne pathogens [19]. AgNPs have been proven to have the potential to inhibit multidrug-resistant bacterial isolates, including Clostridial species. However, the role of AgNPs as biofilm inhibitors has not been investigated for $C$. perfringens isolates.

The relatedness of $C$. perfringens isolates from various sources has been previously reported using many typing methods, such as phage typing, serotyping, plasmid profile typing, ribotyping, multi-locus sequence typing (MLST), pulse-field gel electrophoresis, and repetitive element PCR (rep-PCR). Unfortunately, most of these methods are not always available in microbiology laboratories, and are technically fastidious and time-consuming. However, randomly amplified polymorphic DNA (RAPD) is a rapid typing method that is suitable and easily applicable in laboratories and is available for epidemiological tracing of the sources of infection [20].

Scarce information is available on the relative occurrence of $\alpha$-toxigenic and enterotoxigenic strains of $C$. perfringens in general populations and camels, particularly in Egypt. Therefore, our study addresses the following: (a) the prevalence of C. perfringens in in- 
testinal and fecal samples from chickens, pigeons, camels, and human consumers; (b) the prevalence of $C$. perfringens in retail chicken and camel meat; (c) toxin typing of the isolates; (d) antibiotic resistance profiles of the isolates; (e) inhibitory effect of AgNPs on biofilm formation ability of the isolates; and (f) genetic relatedness of the isolates from various sources determined by RAPD-PCR.

\section{Materials and Methods}

\subsection{Sampling}

Intestinal contents from freshly slaughtered chickens $(n=50)$ were obtained from flocks suspected to be affected with clostridial infection. The birds from farms were admitted to the Clinic of Avian and Rabbit Medicine Department, Faculty of Veterinary Medicine, Zagazig University, Egypt. Birds admitted to the clinic were subjected to clinical and postmortem examination. Intestinal samples (jejunum and ileum) were obtained from 30 pigeons (Balady) aged from 4 to 8 weeks with a history of depression, growth retardation, dropping of wings, and diarrhea. Additionally, diarrheic feces from camels $(n=50)$ were obtained from Sharkia Governorate, Egypt. Retail meat samples were also obtained from chickens $(n=50)$ and camels $(n=50)$ from retail shops in the study area. From human consumers, diarrheic stool swabs $(n=100)$ were obtained from patients at the outpatient clinic at Al-Ahrar Hospital, Sharkia Governorate, Egypt. Informed verbal/written consent for participation in the study was obtained from all participants, and it was approved by the Committee of Animal Welfare and Research Ethics, Faculty of Veterinary Medicine, Zagazig University, Egypt (protocol no. 118/2019).

\subsection{Bacteriological Examination}

The intestinal contents were directly obtained in sterile cooked meat broth (CMB; TM MEDIA, Titan Biotech Ltd., Delhi ISO 9,001, India). We aseptically homogenized $25 \mathrm{~g}$ chicken meat samples in $225 \mathrm{~mL}$ CMB. The human stool samples were directly enriched in $\mathrm{CMB}$ tubes. The tubes were anaerobically incubated at $37{ }^{\circ} \mathrm{C}$ for $24 \mathrm{~h}$ in an anaerobic jar containing gas generating kits (anaeroGen, OXOID Ltd., Hampshire, UK) for enrichment. For isolation of $C$. perfringens, a loopful from the enriched cultures were streaked onto the surface of reinforced clostridial agar (CM0151, OXOID Ltd., Hampshire, $\mathrm{UK}$ ), and then anaerobically incubated at $37^{\circ} \mathrm{C}$ for $24-48 \mathrm{~h}$ in an anaerobic jar containing gas generating kits. Presumptive shiny, pin-headed, and translucent C. perfringens colonies were biochemically identified using hemolysis tests, Gram stains, sugar fermentation, lecithinase tests, nitrate reduction, and motility tests.

\subsection{Molecular Identification}

We used PCR for confirmation of the biochemically suspected isolates. Following the manufacturer's instructions, the extraction of DNA was conducted for 50 isolates using the QIAamp DNA Mini kit (Qiagen GmbH, Hilden, Germany, Catalog no. 51304).

Typing of $C$. perfringens was conducted by primers specific for alpha $(c p a)$, beta (cpb), epsilon (etx), and iota (iap) toxin-associated genes [21]. Moreover, primers for the amplification of beta2 (cpb2) [22] and enterotoxin-associated genes (cpe) were also used [10].

\subsection{Antimicrobial Susceptibility Testing}

The antibiotic susceptibility of the isolates from chicken, pigeons, camels, and human sources was determined with the broth micro-dilution method. The 14 antibiotics used were penicillin (PEN), ampicillin (AMP), amoxicillin (AMX), ampicillin-sulbactam (SAM), clindamycin (CLI), metronidazole (MTZ), vancomycin (VAN), imipenem (IPM), meropenem (MEM), chloramphenicol (CHL), tetracycline (TET), cefotaxime (CTX), cefoxitin (FOX), and ceftriaxone (CRO). The interpretation criteria for the antibiotics were based on EUCAST (2019), except for TET, CTX, FOX, and CRO, which were according to the Clinical and Laboratory Standards Institute (CLSI) guidelines [23]. The minimum inhibitory concentration (MIC) was determined by double-fold dilution of the antimicrobials 
$(0.125-256 \mu \mathrm{g} / \mathrm{mL})$ in Brucella broth (OXOID Ltd., Hampshire, UK), as recommended by CLSI guidelines (CLSI 2011). The dilution was conducted in sterile 96-well flat microplates $(0.05 \mathrm{~mL} 2 \times$ antimicrobial/well) using fresh culture from overnight growth on blood agar. The culture was suspended in $5 \mathrm{~mL}$ sterile deionized water to achieve $0.5 \mathrm{McFarland}$ turbidity, then $0.1 \mathrm{~mL}$ suspension was added to $11 \mathrm{~mL}$ Brucella broth. Next, $50 \mathrm{~mL}$ of thoroughly mixed suspension was transferred to individual wells of microplates. The MIC was read as the lowest antimicrobial concentration that inhibits visible bacterial growth after anaerobic incubation at $37^{\circ} \mathrm{C}$ for $24 \mathrm{~h}$. Growth control, broth sterility, and C. perfringens ATCC 19574 strain were included in each run to evaluate the method's reliability. The multiple antibiotic resistance (MAR) index was determined as the ratio of the number of antibiotics to which C. perfringens isolates exhibited resistance to the number of drugs for which the isolates were examined [24]. Multidrug resistance (MDR) is defined as the resistance of an isolate to at least one agent in three or more antibiotic classes, while extensively drug-resistant isolates (XDR) are defined as isolates resistant to at least one agent in all but two or fewer antimicrobial categories [25].

\subsection{Biofilm Formation}

The microtiter plate method was employed in evaluating the ability of $C$. perfringens isolates to form a biofilm [26,27]. Colonies under investigation were incubated overnight on blood agar under anaerobic conditions. Each isolate was adjusted to match McFarland obesity tube No. $0.5\left(1.5 \times 10^{8} \mathrm{CFU} / \mathrm{mL}\right)$ in Brucella broth. Then, $20 \mathrm{~mL}$ were distributed in wells of microtiter plates with a flat bottom. Each sample was distributed in three wells containing $180 \mu \mathrm{L}$ tryptic soy broth supplemented with $1 \%$ sterile glucose. The plates were then incubated at $44{ }^{\circ} \mathrm{C}$ for six days under anaerobic conditions. The medium was then discarded, and the wells were washed using $200 \mu \mathrm{L}$ sterile phosphate-buffered saline (PBS) trice to remove non-adherent cells. After drying the plates for $45 \mathrm{~min}$, each well was stained with $110 \mu \mathrm{L}$ crystal violet solution $(0.4 \%)$ for $45 \mathrm{~min}$, followed by washing twice using $350 \mu \mathrm{L}$ distilled water. De-staining was conducted by pipetting $200 \mu \mathrm{L} 95 \%$ ethanol in each well for $45 \mathrm{~min}$. Finally, $100 \mu \mathrm{L}$ of the de-stained solution was transferred to the wells in new sterile microtiter plates, and the amount of crystal violet was measured using an ELISA reader (model: sunrise $\mathrm{R} 4$, serial no. 610000079) at $\mathrm{OD}_{620} \mathrm{~nm}$ after adjustment to zero of the negative control. The experiment was conducted in triplicate, and the data were represented as mean \pm standard deviation. The cut-off value (ODc) was calculated using the formula: ODc $=$ average OD of negative control $+(3 \times$ standard deviation of negative control). The OD of each isolate was obtained by the formula: OD = average OD of the isolate-ODc. The data obtained were used to classify the strains as non, weak, moderate, and strong biofilm producers according to the following equations [28]: non-biofilm producer $=\mathrm{OD} \leq \mathrm{ODc}$; weak biofilm producer $=\mathrm{ODc}<\mathrm{OD} \leq 2 \times$ ODc; moderate biofilm producer $=2 \times$ ODc $<$ OD $\leq 4 \times$ ODc; strong biofilm producer $=4 \times$ ODc $<$ OD [29].

\subsection{Anti-Biofilm Activity of AgNPs- $\mathrm{H}_{2} \mathrm{O}_{2}$}

AgNPs- $\mathrm{H}_{2} \mathrm{O}_{2}$ (Top Superpower-vision) was provided as a commercial product by El-Delta Center for Nanosilver Technology, Mansoura, Egypt. The stock solution of the product comprised $45 \mathrm{~nm}$ silver nanoparticles $(0.00004467 \mathrm{~mL} /$ liter $)$ with hydrogen peroxide ( $50 \%$ liter) and natural herbs, i.e., $\operatorname{mint}(1 \mathrm{~mL} /$ liter $)$, at a concentration of $5 \mathrm{~mL} /$ liter of water. Then, the product was diluted using Mueller-Hinton broth.

Out of 14 strong biofilm-producing isolates, six XDR representative isolates from each source were chosen for the biofilm inhibition experiment. The anti-biofilm activity of the AgNPs was determined qualitatively using the tube method [30]. In brief, $50 \mu \mathrm{L}$ overnight culture of the targeted bacteria in LB broth was further diluted to adjust its turbidity according to $0.5 \mathrm{McF}$ arland Standards $\left(5 \times 10^{5} \mathrm{CFU} / \mathrm{mL}\right)$. The suspension was added to the tubes containing $2 \mathrm{~mL}$ sterilized Brucella broth, and these tubes were incubated at $37^{\circ} \mathrm{C}$ for $24 \mathrm{~h}$ under anaerobic conditions after adding different concentrations of AgNPs (25, 50, 75 , and $100 \mu \mathrm{g} / \mathrm{mL}$ ) in separate tubes. Negative control without the bacterial suspension 
and the positive control left without the addition of AgNPs were also included in the experiment. After incubation, the broth culture was decanted and washed twice with PBS. The inside of the tubes was stained with crystal violet dye $(0.1 \%)$ for $30 \mathrm{~min}$; the excess dye was decanted and gently washed off using deionized water. The tubes were dried, and biofilm formation ability was determined by observing a thin layer of blue film on the walls of the tubes. For quantitative estimation of biofilm formation, six representative isolates were chosen from strong biofilm producers; the microtiter plate assay was used [26,27]. In this method, 96-well microtiter plates were used. The wells were inoculated with $180 \mu \mathrm{L}$ Brucella broth and $10 \mu \mathrm{L}$ culture grown overnight and further diluted to adjust its final concentration to $5 \times 10^{5} \mathrm{CFU} / \mathrm{mL}$ and $10 \mu \mathrm{L}$ AgNPs (concentrations used were $0-100 \mu \mathrm{g} / \mathrm{mL}$ ) and incubated at $37^{\circ} \mathrm{C}$ for $24 \mathrm{~h}$ under anaerobic conditions [30]. Negative and positive controls were also used in the assay using sterile growth medium only and working solution, respectively. The experiment was conducted in triplicate to evaluate its reproducibility, and the values were expressed as the average of the three independent experiments. The percentage of biofilm inhibition was calculated using the following formula according to Kalishwaralal, BarathManiKanth [30]:

$$
1-\frac{\text { OD620 of cells treated with AgNPs }}{\text { OD620 of non-treated control }} \times 100
$$

\subsection{Genotyping}

The genetic relatedness between C. perfringens isolates from chickens, pigeons, camels, and human patients was evaluated using RAPD-PCR [31] as previously described. The fingerprinting data were transformed into a binary code depending on the presence or absence of each band. A dendrogram was generated by the unweighted pair group method with an arithmetic average (UPGMA) and Ward's hierarchical clustering routine. Cluster analysis and dendrogram construction were conducted using SPSS, version 22 (IBM, Armonk, NY, USA, 2013). The discriminatory powers of both methods were measured using Simpson's index of diversity $(D)$, indicating the average probability that a typing system will assign a different type to two unrelated strains randomly sampled from a population. A $D$-value of more than 0.9 indicates good differentiation [32] (Hunter, 1990).

\subsection{Data Analysis}

Data were introduced into $\mathrm{R}$ software (R Core Team, 2019; version 3.5.3) for data visualization. The R package "Complex-Heatmap" was used to build a heatmap based on virulence genes, biofilm category, and antimicrobials tested in isolates from chicken, pigeon, camel, and human consumers [33].

\section{Results}

\subsection{Postmortem Examination of Intestinal Samples from Birds}

Examination of the intestine from chickens showed subclinical NE (Figure 1A,B). Multifocal pale foci of mucosal necrosis were observed from the serosa. The lumen of the intestine was filled with gas bubbles in the broiler. The intestine was filled with thick, brownish watery exudate in the jejunum (Figure 1C,D). Examination of the pigeon's intestine exhibited no evidence of enteritis.

\subsection{Prevalence of C. perfringens in the Examined Samples}

Analysis of the obtained samples revealed the isolation of $50(15.2 \%)$ C. perfringens out of the 330 examined samples (Table 1). A higher isolation rate was obtained from pigeon intestinal contents $(66.7 \%)$. There was no statistically significant difference between the isolation of $C$. perfringens from intestinal content $(20 \%)$ and meat of chickens $(10 \%), p=0.26$, and the prevalence of $C$. perfringens from camels was insignificantly higher in diarrheic feces $(18 \%)$ compared to raw camel meat $(4 \%)(p=0.06)$. In human samples, $4 \%$ were positive for $C$. perfringens. 


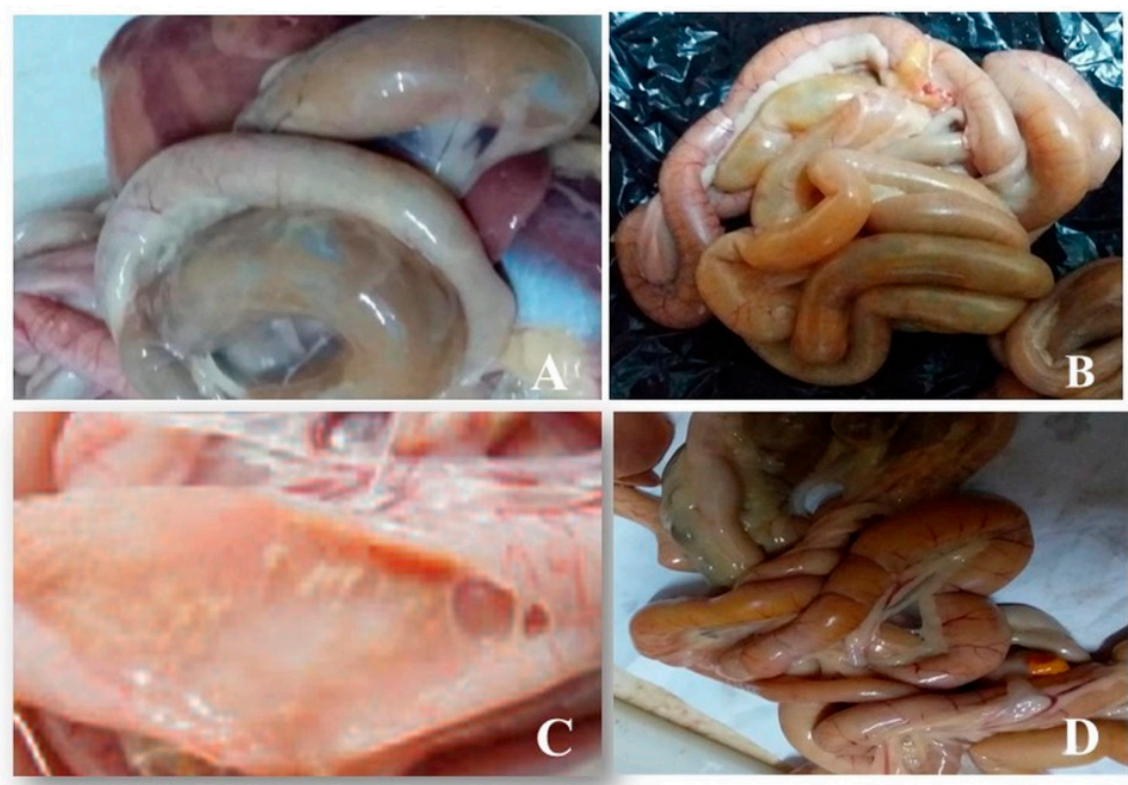

Figure 1. Multifocal pale foci of mucosal necrosis and the lumen of intestine filled with gas bubbles in broiler Hubbard chicken (A,B). Jejunum filled with thick, brownish watery exudate in cobb broiler chicken (C,D).

Table 1. Proportion and count of Clostridium perfringens isolates in chickens, pigeons, camels, and human samples.

\begin{tabular}{|c|c|c|c|c|c|c|}
\hline \multirow{2}{*}{ Species } & \multirow{2}{*}{ Type of Sample } & \multirow{2}{*}{ Number Examined } & \multirow{2}{*}{ Number Positive } & \multicolumn{3}{|c|}{ Genotyping } \\
\hline & & & & $c p a^{+}$ & $c p e^{+}$ & $c p b 2^{+}$ \\
\hline \multirow{2}{*}{ Chickens } & Intestinal content & 50 & $10(20 \%)$ & 10 & 0 & $9(90 \%)$ \\
\hline & Meat & 50 & $5(10 \%)$ & 5 & 0 & $2(40 \%)$ \\
\hline Pigeons & Intestinal content & 30 & $20(66.7 \%)$ & 20 & 0 & $4(20 \%)$ \\
\hline \multirow{2}{*}{ Camels } & Diarrheic feces & 50 & $9(18 \%)$ & 9 & $3(33.3 \%)$ & $7(77.8 \%)$ \\
\hline & Meat & 50 & $2(4 \%)$ & 2 & $1(50 \%)$ & $2(100 \%)$ \\
\hline Humans & Diarrheic stool & 100 & $4(4 \%)$ & 4 & $2(50 \%)$ & $4(100 \%)$ \\
\hline
\end{tabular}

$\mathrm{cpa}^{+}, \mathrm{cpe}^{+}$and $\mathrm{cpb2} 2^{+}$are calculated from the number positive.

\subsection{Toxinotyping of C. perfringens Isolates}

All isolates were of type A (positive for the cpa gene), and only isolates from camel feces $(3,33.3 \%)$, camel meat $(1,50 \%)$, and human stools $(2,50 \%)$ were positive for the cpe gene (Table 1, Figure 2). The $c p b 2$ gene was identified in $28(56 \%)$ of the isolates from all the sources. None of the isolates were found to harbor beta-, iota-, or epsilon-associated genes.

\subsection{Antimicrobial Susceptibility Testing}

Antimicrobial susceptibility testing of $50 \mathrm{C}$. perfringens isolates from different sources revealed the resistance of $82-94 \%$ of the isolates to penicillin, cefotaxime, cefoxitin, ceftriaxone, clindamycin, and chloramphenicol (Table 2, Figure 2). However, all isolates were susceptible to vancomycin, and $86 \%$ exhibited susceptibility to metronidazole. Moreover, $74 \%$ of each of the examined isolates were sensitive to ampicillin, amoxicillin, and ampicillin-sulbactam. Multiple drug resistance was observed in $92 \%$ of the isolates $(46 / 50)$, and the MAR index ranged from 0.28 to 0.9 , with an average of 0.63 (Table 3 ). 


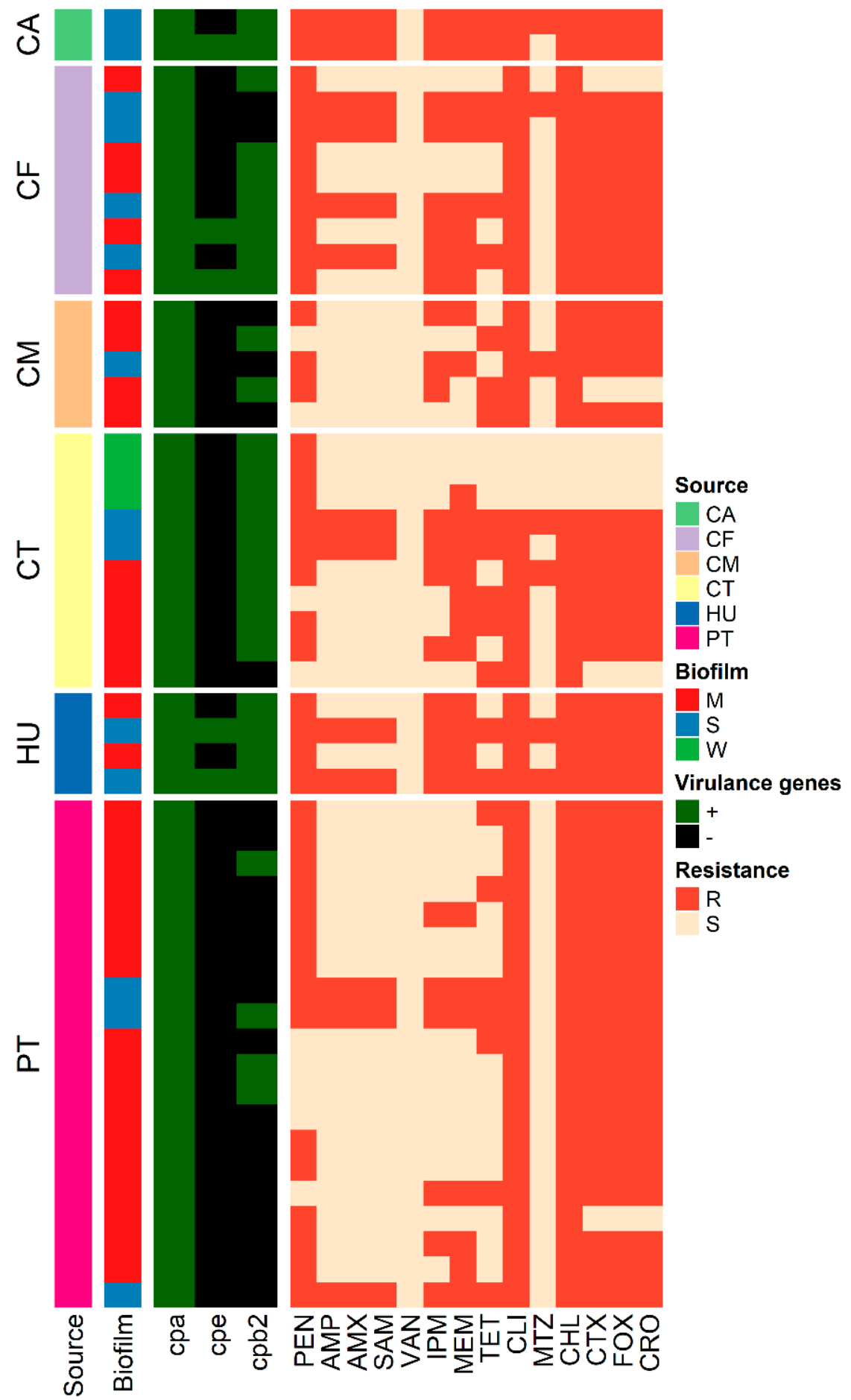

Figure 2. Heat map representation of virulence, biofilm, and antimicrobial resistance profiles of C. perfringens isolates recovered from chicken, pigeon, camels, and human consumers. CT: chicken intestine, CM: chicken meat, PT: pigeon intestine, CF: camel feces, CA: camel meat, HU: human stool, M: moderate, S: strong, W: weak, MAR: multiple antibiotic resistance. Penicillin (PEN), ampicillin (AMP), amoxicillin (AMX), ampicillin-sulbactam (SAM), clindamycin (CLI), metronidazole (MTZ), imipenem (IPM), meropenem (MEM), chloramphenicol (CHL), tetracycline (TET), cefotaxime (CTX), cefoxitin (FOX), and ceftriaxone (CRO). R: resistant, S: sensitive. 
Table 2. Antibiotic susceptibility of 50 Clostridium perfringens isolates from chicken, pigeons, camels, and human sources.

\begin{tabular}{|c|c|c|c|}
\hline Antibiotic Class & Antimicrobial Agent (Abbreviation) & S & $\mathbf{R}$ \\
\hline \multirow{2}{*}{ Penicillins } & Penicillin (PEN) & $9(18 \%)$ & $41(82 \%)$ \\
\hline & Ampicillin (AMP) & $37(74 \%)$ & $13(26 \%)$ \\
\hline \multirow{2}{*}{$\beta$-lactamas } & Amoxicillin (AMX) & $37(74 \%)$ & $13(26 \%)$ \\
\hline & Ampicillin-sulbactam (SAM) & $37(74 \%)$ & $13(26 \%)$ \\
\hline Lincosamides & Clindamycin (CLI) & $3(6 \%)$ & $47(94 \%)$ \\
\hline Nitroimidazole & Metronidazole (MTZ) & $43(86 \%)$ & $7(14 \%)$ \\
\hline Glycopeptides & Vancomycin (VAN) & $50(100 \%)$ & 0 \\
\hline \multirow{2}{*}{ Carbapenems } & Imipenem (IPM) & $25(50 \%)$ & $25(50 \%)$ \\
\hline & Meropenem (MEM) & $22(44 \%)$ & $28(56 \%)$ \\
\hline Phenolics & Chloramphenicole (CHL) & $3(6 \%)$ & $47(94 \%)$ \\
\hline \multirow[t]{2}{*}{ Tetracyclines } & Tetracycline (TET) & $27(54 \%)$ & $23(46 \%)$ \\
\hline & Cefotaxime (CTX) & $7(14 \%)$ & $43(86 \%)$ \\
\hline \multirow[t]{2}{*}{ Cephems } & Cefoxitin (FOX) & $7(14 \%)$ & $43(86 \%)$ \\
\hline & Ceftriaxone (CRO) & $7(14 \%)$ & $43(86 \%)$ \\
\hline
\end{tabular}

Table 3. Toxin type, biofilm category, and antimicrobial resistance profiles of 50 Clostridium perfringens isolates from chicken, pigeons, camels, and human sources.

\begin{tabular}{|c|c|c|c|c|c|c|c|}
\hline \multirow{2}{*}{ ID } & \multirow{2}{*}{ Source } & \multicolumn{3}{|c|}{ Virulence Profile } & \multirow{2}{*}{$\begin{array}{l}\text { Biofilm } \\
\text { Category }\end{array}$} & \multirow{2}{*}{ Resistance Pattern } & \multirow{2}{*}{ MAR Index } \\
\hline & & cpa & cpe & $c p b 2$ & & & \\
\hline CT1 & $\mathrm{CT}$ & + & - & + & W & PEN & - \\
\hline CT4 & $\mathrm{CT}$ & + & - & + & W & PEN & - \\
\hline CT7 & $\mathrm{CT}$ & + & - & + & W & PEN-MEM & - \\
\hline CT11 & $\mathrm{CT}$ & + & - & + & $\mathrm{S}$ & PEN-AMP-AMX-SAM-IPM-MEM-TET-CLI-MTZ-CHL-CTX-FOX-CRO * & 0.9 \\
\hline CT13 & $\mathrm{CT}$ & + & - & + & $S$ & PEN-AMP-AMX-SAM-IPM-MEM-TET-CLI-CHL-CTX-FOX-CRO * & 0.8 \\
\hline CT18 & $\mathrm{CT}$ & + & - & + & M & PEN-IPM-MEM-CLI-MTZ-CHL-CTX-FOX-CRO & 0.6 \\
\hline CT21 & $\mathrm{CT}$ & + & - & + & $\mathrm{M}$ & MEM-CLI-CHL-CTX-FOX-CRO & 0.4 \\
\hline $\mathrm{CT} 25$ & $\mathrm{CT}$ & + & - & + & $\mathrm{M}$ & PEN-MEM-TET-CLI-CHL-CTX-FOX-CRO & 0.5 \\
\hline CT29 & $\mathrm{CT}$ & + & - & + & $\mathrm{M}$ & PEN-IPM-MEM-TET-CLI-CHL-CTX-FOX-CRO & 0.6 \\
\hline CT48 & $\mathrm{CT}$ & + & - & - & $\mathrm{M}$ & CLI-CHL & - \\
\hline CM7 & CM & + & - & - & $\mathrm{M}$ & PEN-IPM-MEM-TET-CLI-CTX-FOX-CRO & 0.5 \\
\hline CM13 & $\mathrm{CM}$ & + & - & + & $\mathrm{M}$ & CLI-CLI-CTX-FOX-CRO & 0.3 \\
\hline CM18 & CM & + & - & - & $\mathrm{S}$ & PEN-IPM-MEM-TET-CLI-MTZ-CHL-CTX-FOX-CRO * & 0.7 \\
\hline CM25 & $\mathrm{CM}$ & + & - & + & $\mathrm{M}$ & PEN-IPM-CLI-CHL & 0.28 \\
\hline CM48 & $\mathrm{CM}$ & + & - & - & $\mathrm{M}$ & TET-CLI-CHL-CTX-FOX-CRO & 04 \\
\hline PT1 & PT & + & - & - & $\mathrm{M}$ & PEN-TET-CLI-CHL-CTX-FOX-CRO & 0.5 \\
\hline PT2 & PT & + & - & - & $\mathrm{M}$ & PEN-TET-CLI-CHL-CTX-FOX-CRO & 0.5 \\
\hline PT3 & PT & + & - & + & $\mathrm{M}$ & PEN-CLI-CHL-CTX-FOX-CRO & 0.4 \\
\hline PT4 & PT & + & - & - & $\mathrm{M}$ & PEN-CLI-CHL-CTX-FOX-CRO & 0.4 \\
\hline PT5 & PT & + & - & - & $\mathrm{M}$ & PEN-IPM-MEM-TET-CLI-CHL-CTX-FOX-CRO & 0.6 \\
\hline PT6 & PT & + & - & - & $\mathrm{M}$ & PEN-CLI-CHL-CTX-FOX-CRO & 0.4 \\
\hline PT8 & PT & + & - & - & M & PEN-CLI-CHL-CTX-FOX-CRO & 0.4 \\
\hline PT11 & PT & + & - & - & S & (PEN-AMP-AMX-SAM-IPM-MEM-TET-CLI-CHL-CTX-FOX-CRO) * & 0.8 \\
\hline PT12 & PT & + & - & + & $\mathrm{S}$ & (PEN-AMP-AMX-SAM-IPM-MEM-TET-CLI-CHL-CTX-FOX-CRO) * & 0.8 \\
\hline PT14 & PT & + & - & - & M & TET-CLI-CHL-CTX-FOX-CRO & 0.4 \\
\hline PT15 & PT & + & - & + & M & CLI-CHL-CTX-FOX-CRO & 0.3 \\
\hline PT16 & PT & + & - & + & M & CLI-CHL-CTX-FOX-CRO & 0.3 \\
\hline PT20 & PT & + & - & - & M & CLI-CHL-CTX-FOX-CRO & 0.3 \\
\hline PT21 & PT & + & - & - & $\mathrm{M}$ & PEN-CLI-CHL-CTX-FOX-CRO & 0.4 \\
\hline PT22 & PT & + & - & - & $\mathrm{M}$ & PEN-CLI-CHL-CTX-FOX-CRO & 0.4 \\
\hline PT26 & PT & + & - & - & $\mathrm{M}$ & IPM-MEM-TET-CLI-CHL-CTX-FOX-CRO & 0.57 \\
\hline PT27 & PT & + & - & - & $\mathrm{M}$ & PEN-CLI-CHL & 0.2 \\
\hline PT28 & PT & + & - & - & $\mathrm{M}$ & PEN-IPM-MEM-CLI-CHL-CTX-FOX-CRO & 0.57 \\
\hline PT29 & PT & + & - & - & $\mathrm{M}$ & PEN-MEM-CLI-CHL-CTX-FOX-CRO & 0.5 \\
\hline PT30 & PT & + & - & - & $\mathrm{S}$ & (PEN-AMP-AMX-SAM-IPM-MEM-TET-CLI-CHL-CTX-FOX-CRO) * & 0.8 \\
\hline CF8 & $\mathrm{CF}$ & + & - & + & M & PEN-CLI-CHL & 0.2 \\
\hline CF13 & $\mathrm{CF}$ & + & - & - & $\mathrm{S}$ & (PEN-AMP-AMX-SAM-IPM-MEM-TET-CLI-MTZ-CHL-CTX-FOX-CRO) * & 0.9 \\
\hline CF16 & $\mathrm{CF}$ & + & - & - & $\mathrm{S}$ & (PEN-AMP-AMX-SAM-IPM-MEM-TET-CLI-CHL-CTX-FOX-CRO) * & 0.8 \\
\hline CF17 & $\mathrm{CF}$ & + & - & + & $\mathrm{M}$ & PEN-CLI-CHL-CTX-FOX-CRO & 0.4 \\
\hline CF18 & CF & + & - & + & $\mathrm{M}$ & PEN-CLI-CHL-CTX-FOX-CRO & 0.4 \\
\hline CF21 & $\mathrm{CF}$ & + & + & + & $S$ & (PEN-AMP-AMX-SAM-IPM-MEM-TET-CLI-CHL-CTX-FOX-CRO) * & 0.8 \\
\hline CF22 & $\mathrm{CF}$ & + & - & + & M & PEN-IPM-MEM-CLI-CHL-CTX-FOX-CRO & 0.57 \\
\hline CF28 & $\mathrm{CF}$ & + & + & + & $\mathrm{S}$ & (PEN-AMP-AMX-SAM-IPM-MEM-TET-CLI-CHL-CTX-FOX-CRO) * & 0.8 \\
\hline
\end{tabular}


Table 3. Cont.

\begin{tabular}{|c|c|c|c|c|c|c|c|}
\hline \multirow{2}{*}{ ID } & \multirow{2}{*}{ Source } & \multicolumn{3}{|c|}{ Virulence Profile } & \multirow{2}{*}{$\begin{array}{l}\text { Biofilm } \\
\text { Category }\end{array}$} & \multirow{2}{*}{ Resistance Pattern } & \multirow{2}{*}{ MAR Index } \\
\hline & & cpa & cpe & $c p b 2$ & & & \\
\hline CF31 & CF & + & + & + & $\mathrm{M}$ & PEN-IPM-MEM-CLI-CHL-CTX-FOX-CRO & 0.57 \\
\hline CA38 & $\mathrm{CA}$ & + & - & + & S & (PEN-AMP-AMX-SAM-IPM-MEM-TET-CLI-MTZ-CHL-CTX-FOX-CRO) * & 0.9 \\
\hline CA49 & $\mathrm{CA}$ & + & + & + & S & (PEN-AMP-AMX-SAM-IPM-MEM-TET-CLI-CHL-CTX-FOX-CRO) * & 0.8 \\
\hline HU11 & HU & + & - & + & M & PEN-IPM-MEM-CLI-CHL-CTX-FOX-CRO & 0.57 \\
\hline HU19 & HU & + & + & + & $\mathrm{S}$ & (PEN-AMP-AMX-SAM-IPM-MEM-TET-CLI-MTZ-CHL-CTX-FOX-CRO) * & 0.9 \\
\hline HU38 & HU & + & - & + & M & PEN-IPM-MEM-CLI-CHL-CTX-FOX-CRO & 0.57 \\
\hline HU47 & $\mathrm{HU}$ & + & + & + & $\mathrm{S}$ & (PEN-AMP-AMX-SAM-IPM-MEM-TET-CLI-MTZ-CHL-CTX-FOX-CRO) * & 0.9 \\
\hline
\end{tabular}

CT: chicken intestine, CM: chicken meat, PT: pigeon intestine, CF: camel feces, CA: camel meat, HU: human stool, M: moderate, S: strong, W: weak, MAR: multiple antibiotic resistance. Penicillin (PEN), ampicillin (AMP), amoxicillin (AMX), ampicillin-sulbactam (SAM), clindamycin (CLI), metronidazole (MTZ), imipenem (IPM), meropenem (MEM), chloramphenicol (CHL), tetracycline (TET), cefotaxime (CTX), cefoxitin (FOX), and ceftriaxone (CRO). * XDR isolates (extensively resistant isolates).

\subsection{Biofilm Formation}

C. perfringens isolates under investigation were all biofilm producers, of which $14(28 \%)$ were strong biofilm producers with an average OD620 of $0.5037 \pm 0.03$. All strong biofilmproducing isolates were resistant to at least ten antimicrobials with an MAR index of 0.7 or more, and they were classified as XDR isolates (Table 3). Moderate biofilm producers encountered $60 \%(30 / 50)$ of the isolates, and they were MDR with MAR indices of 0.2-0.6.

\subsection{Anti-Biofilm Activity of $\mathrm{AgNPs}-\mathrm{H}_{2} \mathrm{O}_{2}$}

The effect of AgNPs on biofilm production of six representative C. perfringens isolates was estimated by the qualitative tube method using various concentrations of AgNPs. Positive results were indicated by the presence of a thin layer of biofilms after staining with the dye. The isolates from chicken, camels, and humans required a concentration of $100 \mu \mathrm{g} / \mathrm{mL}$ to inhibit biofilm formation. In the case of the isolate from pigeons, no biofilm production was observed at $75 \mu \mathrm{g} / \mathrm{mL}$ concentration (Table 4).

Table 4. Qualitative estimation of color intensity of biofilm formation by tube method in absence and presence of silver nanoparticles (AgNPs) at different concentrations on Clostridium perfringens isolates.

\begin{tabular}{|c|c|c|c|c|c|c|}
\hline \multirow{2}{*}{ Isolate } & \multirow{2}{*}{ Positive Control } & \multirow{2}{*}{ Negative Control } & \multicolumn{4}{|c|}{ AgNP Concentrations $(\mu \mathrm{g} / \mathrm{mL})$} \\
\hline & & & 25 & 50 & 75 & 100 \\
\hline CT11 & ++++ & - & +++ & ++ & + & - \\
\hline CM18 & ++++ & - & +++ & ++ & + & - \\
\hline PT11 & ++++ & - & +++ & + & - & - \\
\hline CF13 & ++++ & - & +++ & ++ & + & - \\
\hline CA49 & ++++ & - & +++ & ++ & + & - \\
\hline HU19 & ++++ & - & +++ & ++ & + & - \\
\hline
\end{tabular}

CT: chicken intestine, CM: chicken meat, PT: pigeon intestine, CF: camel feces, CA: camel meat, HU: human stool.

The quantitative biofilm estimation was conducted using the microtiter plate method, and the inhibition percentage of biofilm production with different AgNP concentrations was investigated. The inhibition of biofilm formation by C. perfringens isolates was dosedependent. At the highest concentration of AgNPs $(100 \mu \mathrm{g} / \mathrm{mL})$, the six examined isolates showed inhibition percentages of 80.8-82.8\% (Figure 3 and Supplementary Tables S1 and S2).

\subsection{Genotyping}

The RAPD-PCR patterns of the 50 C. perfringens isolates from different sources were investigated by a single amplification profile. The multiple DNA fragments ranged in size from 300 to $2700 \mathrm{bp}$. The primer sets manufactured 33 profiles (referred to as R1-R33). The discriminatory power of the RAPD-PCR was calculated using Simpson's index of diversity, and the $D$-value was 0.9763 , which indicated a high discriminatory power. The 
dendrogram analysis of the examined isolates $(n=50)$ showed four clusters (Figure 4$)$. The similarity between the human, pigeon, and camel isolates in the same cluster was $100 \%$.

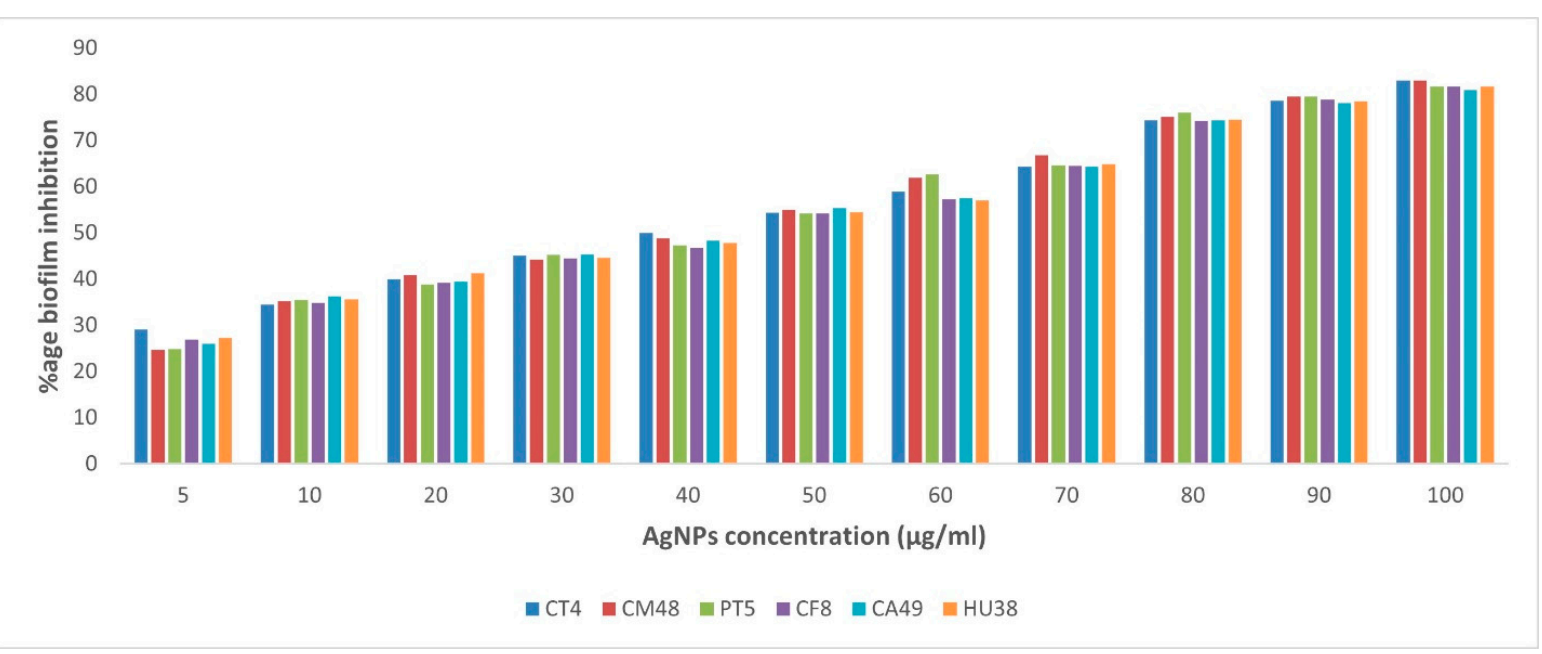

Figure 3. Percent inhibition of biofilm formation by various concentrations of AgNPs against Clostridium perfringens. The absorbance was measured at $620 \mathrm{~nm}$ for the quantification of biofilm formation. CT: chicken intestine, CM: chicken meat, PT: pigeon intestine, CF: camel feces, CA: camel meat, HU: human stool.

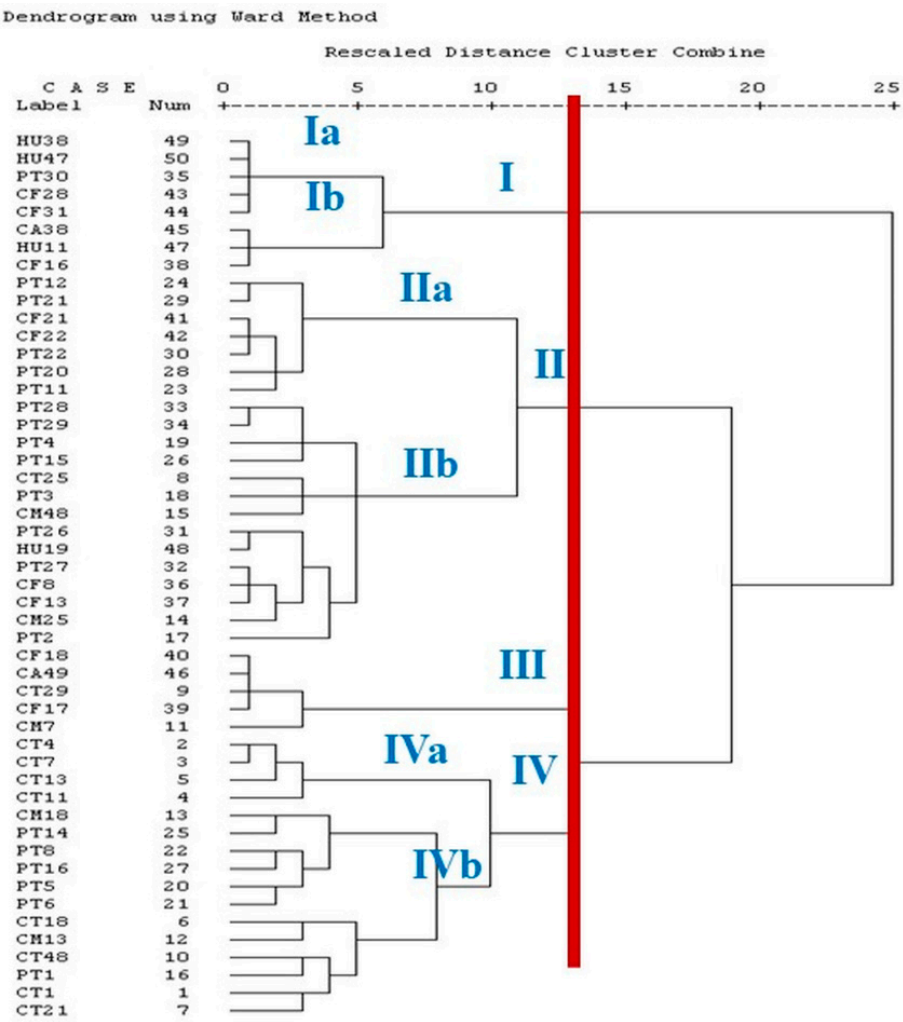

Figure 4. Dendrogram showing the relatedness of $C$. perfringens isolated from different sources as determined by RAPD-PCR fingerprinting using the SPSS computer software program. (CT: chicken intestine, CM: chicken meat, PT: pigeon intestine, CF: camel feces, CA: camel meat, HU: human stool).

\section{Discussion}

C. perfringens is known as a major public health risk, causing diseases in animals and humans; it also causes economic losses, especially in poultry flocks [34]. This study 
investigated the prevalence of $C$. perfringens in various sources of animal and human origin. Toxin typing, antibiotic resistance profile, genotyping, biofilm formation ability, and the effect of silver nanoparticles on biofilm were also evaluated. The source of chicken meat contamination is mainly the intestinal contents during slaughtering and processing [4]. Fifty $C$. perfringens isolates were recovered from all the examined sources, and all the isolates were of type A. In our study, the isolation rate of C. perfringens was higher in pigeon intestines $(66.7 \%)$, followed by chicken intestines $(20 \%)$. The high prevalence of $C$. perfringens in chickens and pigeons could be attributed to the colonization of the organism in the intestinal tract early in poultry life, even from hatchery [35].

A study in Egypt reported that $41.7 \%$ of broiler chickens were infected with C. perfringens, of which $35.4 \%$ were asymptomatic [36]. In China, $23.1 \%$ of live poultry from farms and markets was positive, while $13.6 \%$ of fresh chicken meat was positive [4]. In Jordan, $43.2 \%$ of broiler chicken flocks were positive [37]. C. perfringens in poultry has acute clinical or sub-clinical forms. The acute disease leads to a high mortality rate and accounts for $1 \%$ of deaths per day [38]. The subclinical form is characterized by damage to the intestinal mucosa, which results in decreased digestion and absorption, reduced weight gain, and increased feed conversion ratio [39]. Although healthy birds usually contain less than $10^{5}$ colony-forming units (CFU) of $C$. perfringens per gram of digesta, NE is produced due to the proliferation of pathogenic C. perfringens strains to reach $10^{7}$ and $10^{9} \mathrm{CFU}$ per gram of digesta [40].

Regarding pigeons, scarce studies reported the prevalence of $C$. perfringens; for instance, Rahman, Sharma [41] reported an isolation rate of 33.3\%. Despite the high isolation rate in pigeon intestine, no NE lesions were observed. However, the birds under investigation had symptoms of diarrhea and growth retardation. This could be explained by the presence of another microbial pathogen, which in turn decreased the immunity of the pigeons, thus causing the high isolation rate of $C$. perfringens [42].

All C. perfringens toxin types produce alpha-toxin; however, higher amounts of the toxin are produced by type A than the other types [43]. Necrotic enteritis and the subclinical form of $C$. perfringens infection in poultry are caused by $C$. perfringens type $A$, and to a lesser extent type C [44]. The predominance of type A from NE cases has been reported in different studies $[4,37,45]$. The main source of infection for chickens in farms and outlets is crossinfection via feces; therefore, proper hygienic measures, including disposal of contaminated bedding, are crucial to control C. perfringens infections in farms and markets [4].

None of the chicken or pigeon isolates harbored the cpe gene, whereas the $c p b 2$ gene was identified in $73.3 \%(11 / 15)$ of isolates of chicken origin and $20 \%(4 / 20)$ of isolates of pigeon origin. Accordingly, Gharaibeh, A1 Rifai [37] reported the isolation of C. perfringens type A isolates from chicken flocks suffering from enteritis, and the isolates were not positive for enterotoxin-associated genes. In Jordan, all isolates recovered from broiler chickens with enteritis were classified as type A and non-enterotoxin producers [37]. Similar results were also reported in Finland [46] and Sweden [44]. Beta2 toxins have been associated with enteric diseases in humans and other animals and NE in birds [47]. This explains our findings where $c p b 2$ gene was recovered from all examined sources with variable percentages.

In our study, C. perfringens type A was recovered from $10 \%$ of retail chicken meat samples. In Belgium, 100\% of C. perfringens isolates from chicken meat were of type A [48], which suggests that cpa might be a universal gene in C. perfringens isolated from meat samples [49]. In Korea, 11.1\% [50] and 33\% [12] of retail chicken meat samples were positive for C. perfringens, while in Jordan, $43 \%$ of chicken meat samples were positive [37]. Chicken and ground chicken meat examined in Japan for C. perfringens contamination showed that $97 \%$ and $100 \%$ of the samples were positive, respectively [51]. The cpe gene, which encodes the enterotoxin, is reported in less than 5\% of C. perfringens isolates [52]. All our chicken isolates were cpe-negative. In accordance, none of the isolates from chicken and beef meat samples were positive for other toxin encoding genes other than the cpa gene [12] However, in the USA and Japan, only 1-3\% of C. perfringens isolates from chicken harbored 
the cpe gene $[10,53]$. Another study in Japan reported $0.5-0.7 \%$ cpe-positive isolates from beef samples [10].

The high detection rate of the cpa gene in C. perfringens isolates could be attributable to the presence of the gene on the chromosome. While, $c p b$, etx, and iap are located on plasmids, the cpe could be found either on chromosomes or plasmids [7]. Therefore, acquisition or loss of plasmids might have a role in changing toxin types [49]. In our study, the absence of genes except cpa could be explained by the loss of mobile genetic elements, and this is following a previous study [12]. Furthermore, the carriage of the cpe gene was reported to vary; in food poisoning isolates, it is on the chromosome, while it is on the transferable plasmids in isolates from other gastrointestinal (GI) diseases, such as antibiotic-associated diarrhea [51].

The first report on beta2 toxin and its encoding gene (cpb2) was in C. perfringens type $C$ isolates from necrotizing enterocolitis in a piglet [54]. No significant homologies were observed between the amino acid sequence of $c p b 2$ and $c p b$ from the beta toxin [55]. The beta2 toxin was found to possess a weaker cytotoxic activity than the beta toxin, despite having similar biological activity [54]. However, a possible association was reported between enteric disease and the presence of $C$. perfringens isolates carrying the $c p b 2$ gene [56,57]. In this study, the $c p b 2$ gene was identified from C. perfringens strains isolated from chickens, pigeons, camels, and human sources. Our results conform with previously published studies that identified the $c p b 2$ gene in isolates from chickens [56,58], humans [47], and camels [58]. A recent study in Egypt documented a high frequency of the $c p b 2$ gene from C. perfringens isolates in various sources, including chickens and humans [59]. In the USA, all isolates from chicken and human patients were of type A, and the $c p b 2$ gene was isolated from $93 \%$ and $65 \%$ of chicken and human isolates, respectively [60]. An investigation of food poisoning outbreaks showed that undercooked meat contaminated with C. perfringens resulted in the survival and growth of the organism, which spread to other servings, causing food poisoning in consumers [61]. Nearly $70 \%$ of $C$. perfringens food poisoning outbreaks and $20 \%$ of all non-foodborne gastrointestinal diseases are caused by enterotoxigenic C. perfringens [5]. In Korea, $33 \%$ of chicken meat samples were positive for C. perfringens and all isolates were of type $\mathrm{A}$, with positive results for only the cpa gene and harmful for the cpe, cpb, etx, iap, and netB genes [12].

Fewer studies have documented the isolation of $C$. perfringens from camels; in our study, $18 \%$ of diarrheic feces from camels were identified, and all nine isolates were of type A, of which seven (77.8\%) and three (33.3\%) were positive for cpb2 and cpe genes, respectively. According to Fayez, Elsohaby [62], the isolation of C. perfringens from diarrheic calves and adults was $73.7 \%$, and most of the isolates were of type A. Moreover, other studies have reported that $C$. perfringens type $A$ is the predominant type from camels and other animals $[63,64]$. Scarce information has been reported regarding the occurrence of C. perfringens in camel meat. Our results showed that two (4\%) retail camel meat samples were contaminated, and one isolate was positive for the cpe gene, while both isolates harbored the $c p b 2$ gene. These findings show the potential of camel meat to serve as a source of $C$. perfringens. The presence of $c p b 2$ gene is correlated with gastrointestinal diseases in humans and other animals. The two isolates from camel meat in our study were XDR and strong biofilm producers, thus showing the potential of these isolates to cause foodborne gastroenteritis in human consumers. Previous studies have reported the isolation of $C$. perfringens from retail meat from various animals $[10,65]$. These results exhibit the urgent need for high sanitary conditions during the slaughter of animals and during the retail of meat at markets to minimize the risk of foodborne intoxication caused by C. perfringens [65].

Healthy people carry less than $10^{5} \mathrm{C}$. perfringens $\mathrm{CFU} / \mathrm{g}$ feces, while diarrheic patients may carry $10^{6}$ or more CFU/g [66]. The intestinal carriage of $C$. perfringens may be diverse, and some healthy subjects may also act as potential reservoirs of more than one $C$. perfringens strain [6]. In this study, C. perfringens isolates were recovered from $4 \%$ of human stool from diarrheic patients and were positive for $c p a$ and $c p b 2$, while two were positive for the 
enterotoxin-associated cpe gene. In Ireland, C. perfringens was isolated from $7.6 \%$ of fecal samples from elderly subjects [67].

Yadav, Das [68] identified 43.8\% C. perfringens type A isolates from human diarrheal cases, of which $49.1 \%$ were found to have only the cpa gene, and $35.1 \%$ were positive for $c p a$ and $c p b 2$. The diversity of the study population and the methods of detection could be the reason for the higher carriage of $C$. perfringens compared to this study [6].

C. perfringens isolates in this study showed resistance to penicillin, tetracycline, cefotaxime, cefoxitin, ceftriaxone, clindamycin, and chloramphenicol. This occurred following a study on $C$. perfringens from camels and herders; the findings indicated less effective antimicrobial activity of penicillin and cephems [62]. The use of penicillin and tetracycline as growth promotors and for the control of Gram-positive bacterial infections may explain the resistance reported in our study to these drugs [69]. In contrast, penicillin and tetracyclines exhibited sufficient activity against C. perfringens isolates from chicken and human isolates [37,59]. Clindamycin was reported to be effective against C. perfringens isolates [70]. However, our results showed a high resistance rate of $94 \%$, which is comparable with other studies [71,72]. The low resistance of the isolates to ampicillin, amoxicillin, and ampicillin-sulbactam coincides with another study in Egypt [59]. C. perfringens isolates were resistant to amoxicillin, ampicillin, cefotaxime, tetracycline, and clindamycin at rates of $16.1 \%, 29.8 \%, 11.3 \%, 63.7 \%$, and $70.8 \%$, respectively [4]. Another study reported that the most resistant antimicrobial agent for the C. perfringens isolates was tetracycline (33/33, $100 \%)$, followed by imipenem (24/33, 72.7\%), and 27 of the 33 strains (81.8\%) were multiple drug-resistant, exhibiting resistance to at least three classes of antimicrobials [12].

Multidrug resistance was observed in $92 \%$ of the isolates, of which $26 \%$ were XDR, and the MAR indices ranged from 0.28 to 0.9 with an average of 0.63 . These findings conform with previous studies that showed the wide spread of MDR and XDR C. perfringens isolates due to the uncontrolled use of these drugs as growth promoters in animals and for therapeutic uses in humans and animals, which has caused increased resistance [59,62]. It has been shown that MAR higher than 0.2 could be due to contamination from high-risk sources, such as humans and farm animals frequently exposed to antibiotics, thus resulting in potential risk to consumers [73].

Biofilm-forming microbes are responsible for causing $65-80 \%$ of infections because they can resist environmental and physical conditions and antibiotic treatment [74]. Although most studies focus on biofilm production and methods of reduction in single species, biofilms in nature mostly comprise multiple species, where inter-species interactions can affect the development, structure, and function of these communities [75]. These interactions could be in the forms of genetic and metabolic exchange and signaling to occur between microorganisms in biofilm communities; however, high throughput and high-resolution methods are needed to reveal these interactions [76]. Such interactions could be either competitive or cooperative, resulting in impacts on maturation, physiology, antimicrobial resistance, and virulence of these communities [76].

All our isolates were biofilm producers, and $28 \%$ produced strong biofilms, conforming with another study in Egypt [59]. Biofilms produced by C. perfringens isolates contribute to developing gastrointestinal diarrheal diseases in humans and animals due to the protective effect of biofilms against antibiotic treatment [26]. Several studies have reported the ability of $C$. perfringens isolates from different sources to produce biofilms $[26,27,50,59]$. Therefore, to control infections caused by biofilm-producing microbes, biofilm inhibitors should be used.

The chemical, biological, and physical complexity and dynamics of EPs resulted in poor susceptibility to antimicrobial agents [15]. The extracellular polymeric substances either bind to antimicrobials, delaying their diffusion, or they chemically react with antimicrobials, causing inactivation [77]. Therefore, nanoparticles have been used as alternatives for biofilm eradication. Nanoparticles play an important role as carriers of EPS matrix disruptors due to their intrinsic high surface area to volume ratio, providing a platform for 
the development of materials with a wide spectrum of mechanical, chemical, electrical, and magnetic properties [78].

The use of NPs in inhibiting biofilms has been previously documented for various bacteria [79-81]. This study indicated the potential of AgNPs to inhibit biofilm production at concentrations of 75 and $100 \mu \mathrm{g} / \mathrm{mL}$, and the percentage of inhibition was $80.8-82.8 \%$ at the highest AgNP concentrations. The inhibitory effect of AgNPs was previously reported by Siddique, Aslam [81] on biofilm production by Klebsiella pneumoniae isolates. The results revealed $23-86 \%$ inhibition in the presence of different concentrations of AgNPs due to the disruption of the EPS matrix. Moreover, other studies reported $89 \%$ and $75 \%$ biofilm inhibition in Staphylococcus aureus and Escherichia coli, respectively [82]. Studies also demonstrated that nanosized silver (at the size of $100 \mathrm{nM}$ ) resulted in a $95 \%$ reduction in biofilm production by Pseudomonas aeruginosa due to the disruption of the EPS matrix [83].

Tracing the source and route of transmission of $C$. perfringens type A strains causing food poisoning is significant in epidemiological investigations. RAPD-PCR is one of the effective methods used for studying the genetic relationship of $C$. perfringens isolates from various sources [20]. Our results indicated that $50 \mathrm{C}$. perfringens isolates recovered from various sources were grouped in four clusters. One of the clusters included isolates from humans, pigeons, and camels with $100 \%$ similarity, showing a common source of the isolates. Similar results were reported by Afshari, Jamshidi [20], who obtained C. perfringens isolates from human stool, poultry meat, and minced meat in the same cluster. The discriminatory power of RAPD-PCR in our study was 0.9763 , which was a high discrimination of the reaction to the isolates from various sources. Our isolates of chicken and pigeon origin were genetically clustered more closely to each other, and this was consistent with a previous study [84].

The control of biofilm-producing bacteria especially in the food chain depends mainly on the identification of their levels and tracing their sources. Bacterial biofilms possess high resistance to commercial antimicrobial agents, which necessitate the need for finding control alternatives. The inhibitory action of AgNPs- $\mathrm{H}_{2} \mathrm{O}_{2}$ on bacterial biofilms make it a promising wide-spectrum antibacterial agent. Because of the ecofriendly nature of the product, it can be safely used in the food industry, protecting human health. Further studies are required to find more antimicrobial alternatives for food safety.

\section{Conclusions}

In conclusion, MDR and XDR C. perfringens type A are predominant in chickens, pigeons, camels, and humans in the study area. The potential of the isolates to manufacture illness is predicted because of the presence of $c p e$ and $c p b 2$ genes. The anti-biofilm activity of AgNPs is described in the study against MDR and XDR C. perfringens isolates. This is the first report of AgNPs anti-biofilm activity against $C$. perfringens in chickens, pigeons, camels, and humans to the best of our knowledge. The RAPD-PCR method seems promising for the epidemiological investigation of foodborne diseases caused by C. perfringens and for contamination source tracking in the field of food hygiene and industry.

Supplementary Materials: The following supporting information can be downloaded at: https: / / www.mdpi.com/article/10.3390/vetsci9030109/s1, Table S1: title. Average OD620 of biofilm production by Clostridium perfringens in the presence of different AgNPs concentrations. Table S2: Percent inhibition of biofilm formation by various concentrations of AgNPs against Clostridium perfringens. The absorbance was measured at $620 \mathrm{~nm}$ for the quantification of biofilm formation.

Author Contributions: H.A.A., R.M.E.B. and H.M.N.T. designed the study; R.M.E.B., R.I.H., R.A.M., F.A.E.-G., H.M.N.T., A.A.H. and E.E. participated in the sampling, bacteriological examination, and antibiotic sensitivity testing; H.A.A. conducted the biofilm experiment and genotyping; H.A.A. wrote the manuscript. All authors contributed to the analysis of the data. All authors have read and agreed to the published version of the manuscript.

Funding: This research received no external funding. 
Institutional Review Board Statement: Informed verbal/written consent for participation in the study was obtained from all participants, and it was approved by the Committee of Animal Welfare and Research Ethics, Faculty of Veterinary Medicine, Zagazig University, Egypt (protocol no. $118 / 2019)$.

Informed Consent Statement: Informed consent was obtained from all subjects involved in the study.

Data Availability Statement: The data are included in the Supplementary Materials.

Conflicts of Interest: The authors declare no conflict of interest.

\section{References}

1. Stanley, D.; Wu, S.B.; Rodgers, N.; Swick, R.A.; Moore, R.J. Differential responses of cecal microbiota to fishmeal, Eimeria and Clostridium perfringens in a necrotic enteritis challenge model in chickens. PLoS ONE 2014, 9, e104739. [CrossRef] [PubMed]

2. Wernery, U.; Seifert, H.S.; Billah, A.M.; Ali, M. Predisposing factors in enterotoxemias of camels (Camelus dromedarius) caused by Clostridium perfringens type A. Rev. Elev. Med. Vet. Pays Trop. 1991, 44, 147-152.

3. Ignacio, A.; Fernandes, M.R.; Rodrigues, V.A.A.; Groppo, F.C.; Cardoso, A.L.; Avila-Campos, M.J.; Nakano, V. Correlation between body mass index and faecal microbiota from children. Clin. Microbiol. Infect. 2016, 22, 258.e251-258.e258. [CrossRef] [PubMed]

4. Zhang, T.; Zhang, W.; Ai, D.; Zhang, R.; Lu, Q.; Luo, Q.; Shao, H. Prevalence and characterization of Clostridium perfringens in broiler chickens and retail chicken meat in central China. Anaerobe 2018, 54, 100-103. [CrossRef]

5. Carman, R.J.; Sayeed, S.; Li, J.; Genheimer, C.W.; Hiltonsmith, M.F.; Wilkins, T.D.; McClane, B.A. Clostridium perfringens toxin genotypes in the feces of healthy North Americans. Anaerobe 2008, 14, 102-108. [CrossRef]

6. Nagpal, R.; Ogata, K.; Tsuji, H.; Matsuda, K.; Takahashi, T.; Nomoto, K.; Suzuki, Y.; Kawashima, K.; Nagata, S.; Yamashiro, Y. Sensitive quantification of Clostridium perfringens in human feces by quantitative real-time PCR targeting alpha-toxin and enterotoxin genes. BMC Microbiol. 2015, 15, 219. [CrossRef] [PubMed]

7. Rood, J.I.; Adams, V.; Lacey, J.; Lyras, D.; McClane, B.A.; Melville, S.B.; Moore, R.J.; Popoff, M.R.; Sarker, M.R.; Songer, J.G.; et al. Expansion of the Clostridium perfringens toxin-based typing scheme. Anaerobe 2018, 53, 5-10. [CrossRef] [PubMed]

8. Miyamoto, K.; Wen, Q.; McClane, B.A. Multiplex PCR genotyping assay that distinguishes between isolates of Clostridium perfringens type A carrying a chromosomal enterotoxin gene (cpe) locus, a plasmid cpe locus with an IS1470-like sequence, or a plasmid cpe locus with an IS1151 sequence. J. Clin. Microbiol. 2004, 42, 1552-1558. [CrossRef] [PubMed]

9. Songer, J.G.; Uzal, F.A. Clostridial enteric infections in pigs. J. Vet. Diagn. Invest. 2005, 17, 528-536. [CrossRef] [PubMed]

10. Miki, Y.; Miyamoto, K.; Kaneko-Hirano, I.; Fujiuchi, K.; Akimoto, S. Prevalence and characterization of enterotoxin genecarrying Clostridium perfringens isolates from retail meat products in Japan. Appl. Environ. Microbiol. 2008, 74, 5366-5372. [CrossRef] [PubMed]

11. Bueschel, D.M.; Jost, B.H.; Billington, S.J.; Trinh, H.T.; Songer, J.G. Prevalence of cpb2, encoding beta2 toxin, in Clostridium perfringens field isolates: Correlation of genotype with phenotype. Vet. Microbiol. 2003, 94, 121-129. [CrossRef]

12. Jang, Y.-S.; Kim, D.-H.; Bae, D.; Kim, S.-H.; Kim, H.; Moon, J.-S.; Song, K.-Y.; Chon, J.-W.; Seo, K.-H. Prevalence, toxin-typing, and antimicrobial susceptibility of Clostridium perfringens from retail meats in Seoul, Korea. Anaerobe 2020, 64, 102235. [CrossRef] [PubMed]

13. Sherwood, J.E.; Fraser, S.; Citron, D.M.; Wexler, H.; Blakely, G.; Jobling, K.; Patrick, S. Multi-drug resistant Bacteroides fragilis recovered from blood and severe leg wounds caused by an improvised explosive device (IED) in Afghanistan. Anaerobe 2011, 17, 152-155. [CrossRef]

14. Silva, R.O.S.; Salvarani, F.M.; Assis, R.A.; Martins, N.R.S.; Pires, P.S.; Lobato, F.C.F. Antimicrobial susceptibility of Clostridium perfringens strains isolated from broiler chickens. Brazil. J. Microbiol. Publ. Brazil. Soc. Microbiol. 2009, 40, 262-264. [CrossRef]

15. Fulaz, S.; Vitale, S.; Quinn, L.; Casey, E. Nanoparticle-Biofilm Interactions: The Role of the EPS Matrix. Trends Microbiol. 2019, 27, 915-926. [CrossRef] [PubMed]

16. Vestby, L.K.; Grønseth, T.; Simm, R.; Nesse, L.L. Bacterial Biofilm and its Role in the Pathogenesis of Disease. Antibiotics 2020, 9 , 59. [CrossRef]

17. Jamal, M.; Ahmad, W.; Andleeb, S.; Jalil, F.; Imran, M.; Nawaz, M.A.; Hussain, T.; Ali, M.; Rafiq, M.; Kamil, M.A. Bacterial biofilm and associated infections. J. Chin. Med. Assoc. 2018, 81, 7-11. [CrossRef]

18. De Jong, W.H.; Borm, P.J.A. Drug delivery and nanoparticles:applications and hazards. Int. J. Nanomed. 2008, 3, 133-149. [CrossRef] [PubMed]

19. Jones, N.; Ray, B.; Ranjit, K.T.; Manna, A.C. Antibacterial activity of ZnO nanoparticle suspensions on a broad spectrum of microorganisms. FEMS Microbiol. Lett. 2008, 279, 71-76. [CrossRef]

20. Afshari, A.; Jamshidi, A.; Razmyar, J.; Rad, M. Genomic diversity of Clostridium perfringens strains isolated from food and human sources. Iran. J. Vet. Res. 2016, 17, 160-164. [PubMed]

21. Yoo, H.S.; Lee, S.U.; Park, K.Y.; Park, Y.H. Molecular typing and epidemiological survey of prevalence of Clostridium perfringens types by multiplex PCR. J. Clin. Microbiol. 1997, 35, 228-232. [CrossRef] [PubMed]

22. Herholz, C.; Miserez, R.; Nicolet, J.; Frey, J.; Popoff, M.; Gibert, M.; Gerber, H.; Straub, R. Prevalence of beta2-toxigenic Clostridium perfringens in horses with intestinal disorders. J. Clin. Microbiol. 1999, 37, 358-361. [CrossRef] [PubMed] 
23. CLSI. Performance Standards for Antimicrobial Susceptibility Testing. In 21st Informational Supplement. CLSI Supplement M100-S21; Wayne, P.A., Ed.; Clinical and Laboratory Standards Institute: Wayne, PA, USA, 2011; Volume 31, no. 1.

24. Krumperman, P.H. Multiple antibiotic resistance indexing of Escherichia coli to identify high-risk sources of fecal contamination of foods. Appl. Environ. Microbiol. 1983, 46, 165-170. [CrossRef] [PubMed]

25. Magiorakos, A.P.; Srinivasan, A.; Carey, R.B.; Carmeli, Y.; Falagas, M.E.; Giske, C.G.; Harbarth, S.; Hindler, J.F.; Kahlmeter, G.; Olsson-Liljequist, B.; et al. Multidrug-resistant, extensively drug-resistant and pandrug-resistant bacteria: An international expert proposal for interim standard definitions for acquired resistance. Clin. Microbiol. Infect. 2012, 18, 268-281. [CrossRef]

26. Charlebois, A.; Jacques, M.; Archambault, M. Biofilm formation of Clostridium perfringens and its exposure to low-dose antimicrobials. Front. Microbiol. 2014, 5, 183. [CrossRef] [PubMed]

27. Charlebois, A.; Jacques, M.; Boulianne, M.; Archambault, M. Tolerance of Clostridium perfringens biofilms to disinfectants commonly used in the food industry. Food Microbiol. 2017, 62, 32-38. [CrossRef]

28. Saxena, S.; Banerjee, G.; Garg, R.; Singh, M. Comparative Study of Biofilm Formation in Pseudomonas aeruginosa Isolates from Patients of Lower Respiratory Tract Infection. J. Clin. Diagn. Res. JCDR 2014, 8, DC09-DC11. [CrossRef]

29. O'Toole, G.A.; Kolter, R. Initiation of biofilm formation in Pseudomonas fluorescens WCS365 proceeds via multiple, convergent signalling pathways: A genetic analysis. Mol. Microbiol. 1998, 28, 449-461. [CrossRef]

30. Kalishwaralal, K.; BarathManiKanth, S.; Pandian, S.R.K.; Deepak, V.; Gurunathan, S. Silver nanoparticles impede the biofilm formation by Pseudomonas aeruginosa and Staphylococcus epidermidis. Coll. Surf. Bioint. 2010, 79, 340-344. [CrossRef] [PubMed]

31. Leflon-Guibout, V.; Pons, J.L.; Heym, B.; Nicolas-Chanoine, M.H. Typing of Clostridium perfringens strains by use of Random Amplified Polymorphic DNA (RAPD) system in comparison with zymotyping. Anaerobe 1997, 3, 245-250. [CrossRef] [PubMed]

32. Hunter, P.R. Reproducibility and indices of discriminatory power of microbial typing methods. J. Clin. Microbiol. 1990, 28, 1903-1905. [CrossRef]

33. Gu, Z.; Eils, R.; Schlesner, M. Complex heatmaps reveal patterns and correlations in multidimensional genomic data. Bioinformatics 2016, 32, 2847-2849. [CrossRef] [PubMed]

34. Tansuphasiri, U.; Matra, W.; Sangsuk, L. Antimicrobial resistance among Clostridium perfringens isolated from various sources in Thailand. Southeast Asian J. Trop. Med. Public Health 2005, 36, 954-961. [PubMed]

35. Craven, S.E.; Stern, N.J.; Bailey, J.S.; Cox, N.A. Incidence of Clostridium perfringens in broiler chickens and their environment during production and processing. Avian Dis. 2001, 45, 887-896. [CrossRef] [PubMed]

36. Osman, K.M.; Soliman, Y.A.; Amin, Z.M.; Aly, M.A. Prevalence of Clostridium perfringens type A isolates in commercial broiler chickens and parent broiler breeder hens in Egypt. Rev. Sci. Tech. 2012, 31, 931-941. [CrossRef] [PubMed]

37. Gharaibeh, S.; Al Rifai, R.; Al-Majali, A. Molecular typing and antimicrobial susceptibility of Clostridium perfringens from broiler chickens. Anaerobe 2010, 16, 586-589. [CrossRef]

38. Kaldhusdal, M.; Lovland, A. The economical impact of Clostridium perfringens is greater than anticipated. World Poult. 2000, $16,50-51$

39. Kaldhusdal, M.; Schneitz, C.; Hofshagen, M.; Skjerve, E. Reduced incidence of Clostridium perfringens-associated lesions and improved performance in broiler chickens treated with normal intestinal bacteria from adult fowl. Avian Dis. 2001, 45, 149-156. [CrossRef] [PubMed]

40. McDevitt, R.; Brooker, J.; Acamovic, T.; Sparks, N. Necrotic enteritis; a continuing challenge for the poultry industry. Worlds Poult. Sci. J. 2006, 62, 221-247. [CrossRef]

41. Rahman, M.S.; Sharma, R.; Borah, P.; Chakraborty, A.; Devi, M.R.; Longjam, N. Characterization of Clostridium perfringens isolated from mammals and birds from Guwahati city, India. J. Venom. Anim. Toxins Incl. Trop. Dis. 2012, 18, 83-87. [CrossRef]

42. Harlin, R.; Wade, L. Bacterial and parasitic diseases of Columbiformes. Vet. Clin. N. Am. Exot. Anim. Pract. 2009, 12, 453-473. [CrossRef] [PubMed]

43. Canard, B.; Saint-Joanis, B.; Cole, S.T. Genomic diversity and organization of virulence genes in the pathogenic anaerobe Clostridium perfringens. Mol. Microbiol. 1992, 6, 1421-1429. [CrossRef] [PubMed]

44. Engström, B.E.; Fermér, C.; Lindberg, A.; Saarinen, E.; Båverud, V.; Gunnarsson, A. Molecular typing of isolates of Clostridium perfringens from healthy and diseased poultry. Vet. Microbiol. 2003, 94, 225-235. [CrossRef]

45. Mwangi, S.; Timmons, J.; Fitz-coy, S.; Parveen, S. Characterization of Clostridium perfringens recovered from broiler chicken affected by necrotic enteritis. Poult. Sci. 2019, 98, 128-135. [CrossRef]

46. Heikinheimo, A.; Korkeala, H. Multiplex PCR assay for toxinotyping Clostridium perfringens isolates obtained from Finnish broiler chickens. Lett. Appl. Microbiol. 2005, 40, 407-411. [CrossRef]

47. van Asten, A.J.A.M.; Nikolaou, G.N.; Gröne, A. The occurrence of cpb2-toxigenic Clostridium perfringens and the possible role of the $\beta 2$-toxin in enteric disease of domestic animals, wild animals and humans. Vet. J. 2010, 183, 135-140. [CrossRef]

48. Gholamiandehkordi, A.; Eeckhaut, V.; Lanckriet, A.; Timbermont, L.; Bjerrum, L.; Ducatelle, R.; Haesebrouck, F.; Van Immerseel, F. Antimicrobial resistance in Clostridium perfringens isolates from broilers in Belgium. Vet. Res. Commun. 2009, 33, 1031-1037. [CrossRef]

49. Petit, L.; Gibert, M.; Popoff, M.R. Clostridium perfringens: Toxinotype and genotype. Trends Microbiol. 1999, 7, 104-110. [CrossRef]

50. Hu, W.-S.; Kim, H.; Koo, O.K. Molecular genotyping, biofilm formation and antibiotic resistance of enterotoxigenic Clostridium perfringens isolated from meat supplied to school cafeterias in South Korea. Anaerobe 2018, 52, 115-121. [CrossRef] 
51. Sparks, S.G.; Carman, R.J.; Sarker, M.R.; McClane, B.A. Genotyping of enterotoxigenic Clostridium perfringens fecal isolates associated with antibiotic-associated diarrhea and food poisoning in North America. J. Clin. Microbiol. 2001, 39, 883-888. [CrossRef]

52. Freedman, J.C.; Shrestha, A.; McClane, B.A. Clostridium perfringens Enterotoxin: Action, Genetics, and Translational Applications. Toxins 2016, 8, 73. [CrossRef] [PubMed]

53. Wen, Q.; McClane, B.A. Detection of enterotoxigenic Clostridium perfringens type A isolates in American retail foods. Appl. Environ. Microbiol. 2004, 70, 2685-2691. [CrossRef] [PubMed]

54. Gibert, M.; Jolivet-Reynaud, C.; Popoff, M.R. Beta2 toxin, a novel toxin produced by Clostridium perfringens. Gene 1997, 203, 65-73. [CrossRef]

55. Shimizu, T.; Ohtani, K.; Hirakawa, H.; Ohshima, K.; Yamashita, A.; Shiba, T.; Ogasawara, N.; Hattori, M.; Kuhara, S.; Hayashi, H. Complete genome sequence of Clostridium perfringens, an anaerobic flesh-eater. Proc. Nat. Acad. Sci. USA 2002, 99, 996-1001. [CrossRef] [PubMed]

56. Praveen Kumar, N.; Vinod Kumar, N.; Karthik, A. Molecular detection and characterization of Clostridium perfringens toxin genes causing necrotic enteritis in broiler chickens. Trop. Anim. Health Prod. 2019, 51, 1559-1569. [CrossRef] [PubMed]

57. Tolooe, A.; Shojadoost, B.; Peighambari, S. Molecular detection and characterization of $c p b 2$ gene in Clostridium perfringens isolates from healthy and diseased chickens. J. Venom. Anim. Toxins incl. Trop. Dis. 2011, 17, 59-65. [CrossRef]

58. Forti, K.; Ferroni, L.; Pellegrini, M.; Cruciani, D.; De Giuseppe, A.; Crotti, S.; Papa, P.; Maresca, C.; Severi, G.; Marenzoni, M.L.; et al Molecular Characterization of Clostridium perfringens Strains Isolated in Italy. Toxins 2020, 12, 650. [CrossRef]

59. Gharieb, R.; Saad, M.; Abdallah, K.; Khedr, M.; Farag, E.; Abd El-Fattah, A. Insights on toxin genotyping, virulence, antibiogram profiling, biofilm formation and efficacy of disinfectants on biofilms of Clostridium perfringens isolated from poultry, animals and humans. J. Appl. Microbiol. 2021, 130, 819-831. [CrossRef]

60. Park, M.; Rafii, F. The prevalence of plasmid-coded cpe enterotoxin, $\beta 2$ toxin, tpeL toxin, and tetracycline resistance in Clostridium perfringens strains isolated from different sources. Anaerobe 2019, 56, 124-129. [CrossRef]

61. Packer, S.; Day, J.; Hardman, P.; Cameron, J.; Kennedy, M.; Turner, J.; Willis, C.; Amar, C.; Nozad, B.; Gobin, M. A cohort study investigating a point source outbreak of Clostridium perfringens associated with consumption of roasted meat and gravy at a buffet on Mothering Sunday 2018, South West, England. Food Control. 2020, 112, 107097. [CrossRef]

62. Fayez, M.; Elsohaby, I.; Al-Marri, T.; Zidan, K.; Aldoweriej, A.; El-Sergany, E.; Elmoslemany, A. Genotyping and antimicrobial susceptibility of Clostridium perfringens isolated from dromedary camels, pastures and herders. Comp. Immunol. Microbiol. Infect. Dis. 2020, 70, 101460. [CrossRef] [PubMed]

63. Ahmed, Z.A.M. The Role of Clostridium Perfringens in Camel Calf Diarrhoea with Special Reference to the Pathogenesis and Pathology in the Sudan. Ph.D. Thesis, Microbiology Department, Faculty of Veterinary Medicine, University of Khartoum, Khartoum, Sudan, 2004; pp. 1-138.

64. Mohamed, E.M.; Suelam, I.; Saleh, M. The presence of toxin genes of Clostridium perfringens isolated from camels and humans in Egypt. Vet. Arhiv 2010, 80, 383-392.

65. Rodríguez, E.; Gamboa Mdel, M.; Vargas, P. [Clostridium perfringens in raw and cooked meats and its relation with the environment in Costa Rica]. Arch. Latinoam. Nutr. 2002, 52, 155-159. [PubMed]

66. Samuel, S.C.; Hancock, P.; Leigh, D.A. An investigation into Clostridium perfringens enterotoxin-associated diarrhoea. J. Hosp. Infect. 1991, 18, 219-230. [CrossRef]

67. Lakshminarayanan, B.; Harris, H.M.B.; Coakley, M.; O'Sullivan, Ó.; Stanton, C.; Pruteanu, M.; Shanahan, F.; O’Toole, P.W.; Ross, R.P.; On Behalf Of The Eldermet, C. Prevalence and characterization of Clostridium perfringens from the faecal microbiota of elderly Irish subjects. J. Med. Microbiol. 2013, 62, 457-466. [CrossRef]

68. Yadav, J.P.; Das, S.C.; Dhaka, P.; Vijay, D.; Kumar, M.; Mukhopadhyay, A.K.; Chowdhury, G.; Chauhan, P.; Singh, R.; Dhama, K.; et al. Molecular characterization and antimicrobial resistance profile of Clostridium perfringens type A isolates from humans, animals, fish and their environment. Anaerobe 2017, 47, 120-124. [CrossRef]

69. Diarra, M.S.; Malouin, F. Antibiotics in Canadian poultry productions and anticipated alternatives. Front. Microbiol. 2014, 5, 282. [CrossRef]

70. Akhi, M.T.; Bidar Asl, S.; Pirzadeh, T.; Naghili, B.; Yeganeh, F.; Memar, Y.; Mohammadzadeh, Y. Antibiotic Sensitivity of Clostridium perfringens Isolated From Faeces in Tabriz, Iran. Jundis. J. Microbiol. 2015, 8, e20863. [CrossRef]

71. Khanna, N. Clindamycin-resistant Clostridium perfringens cellulitis. J. Tissue Viab. 2008, 17, 95-97. [CrossRef]

72. Lyras, D.; Adams, V.; Ballard, S.A.; Teng, W.L.; Howarth, P.M.; Crellin, P.K.; Bannam, T.L.; Songer, J.G.; Rood, J.I. tISCpe8, an IS1595-family lincomycin resistance element located on a conjugative plasmid in Clostridium perfringens. J. Bacteriol. 2009, 191, 6345-6351. [CrossRef]

73. Landers, T.F.; Cohen, B.; Wittum, T.E.; Larson, E.L. A review of antibiotic use in food animals: Perspective, policy, and potential Publ. Health Rep. 2012, 127, 4-22. [CrossRef]

74. Varga, J.J.; Therit, B.; Melville, S.B. Type IV pili and the CcpA protein are needed for maximal biofilm formation by the gram-positive anaerobic pathogen Clostridium perfringens. Infect. Immun. 2008, 76, 4944-4951. [CrossRef]

75. Burmølle, M.; Ren, D.; Bjarnsholt, T.; Sørensen, S.J. Interactions in multispecies biofilms: Do they actually matter? Trends Microbiol. 2014, 22, 84-91. [CrossRef] [PubMed] 
76. Giaouris, E.; Heir, E.; Desvaux, M.; Hébraud, M.; Møretrø, T.; Langsrud, S.; Doulgeraki, A.; Nychas, G.-J.; Kačániová, M.; Czaczyk, K.; et al. Intra- and inter-species interactions within biofilms of important foodborne bacterial pathogens. Front. Microbiol. 2015, 6, 841. [CrossRef] [PubMed]

77. Anderl, J.N.; Franklin, M.J.; Stewart, P.S. Role of antibiotic penetration limitation in Klebsiella pneumoniae biofilm resistance to ampicillin and ciprofloxacin. Antimicrob. Agents Chemother. 2000, 44, 1818-1824. [CrossRef] [PubMed]

78. Whitesides, G.M. Nanoscience, Nanotechnology, and Chemistry. Small 2005, 1, 172-179. [CrossRef] [PubMed]

79. El-Gohary, F.A.; Abdel-Hafez, L.J.M.; Zakaria, A.I.; Shata, R.R.; Tahoun, A.; El-Mleeh, A.; Abo Elfadl, E.A.; Elmahallawy, E.K. Enhanced Antibacterial Activity of Silver Nanoparticles Combined with Hydrogen Peroxide Against Multidrug-Resistant Pathogens Isolated from Dairy Farms and Beef Slaughterhouses in Egypt. Infect Drug. Resist. 2020, 13, 3485-3499. [CrossRef] [PubMed]

80. Elsayed, M.M.; Elgohary, F.A.; Zakaria, A.I.; Elkenany, R.M.; El-Khateeb, A.Y. Novel eradication methods for Staphylococcus aureus biofilm in poultry farms and abattoirs using disinfectants loaded onto silver and copper nanoparticles. Environ. Sci. Pollut. Res. Int. 2020, 27, 30716-30728. [CrossRef]

81. Siddique, M.H.; Aslam, B.; Imran, M.; Ashraf, A.; Nadeem, H.; Hayat, S.; Khurshid, M.; Afzal, M.; Malik, I.R.; Shahzad, M.; et al. Effect of Silver Nanoparticles on Biofilm Formation and EPS Production of Multidrug-Resistant Klebsiella pneumoniae. BioMed Res. Int. 2020, 2020, 6398165. [CrossRef]

82. Goswami, S.R.; Sahareen, T.; Singh, M.; Kumar, S. Role of biogenic silver nanoparticles in disruption of cell-cell adhesion in Staphylococcus aureus and Escherichia coli biofilm. J. Indust. Eng. Chem. 2015, 26, 73-80. [CrossRef]

83. Fattah, K.; Gamal, A.; Ibrahim, S.; Mohamed, E.; Saleh, A. Investigation of the efficacy of synthesized silver and zinc oxide nanoparticles against multi-drug resistant gram negative bacterial clinical isolates. Arch Clin. Microbiol. $2017,8,67$.

84. Hastey, C.J.; Boyd, H.; Schuetz, A.N.; Anderson, K.; Citron, D.M.; Dzink-Fox, J.; Hackel, M.; Hecht, D.W.; Jacobus, N.V.; Jenkins, S.G.; et al. Changes in the antibiotic susceptibility of anaerobic bacteria from 2007-2009 to 2010-2012 based on the CLSI methodology. Anaerobe 2016, 42, 27-30. [CrossRef] [PubMed] 